\title{
EMPRESA, SUSTENTABILIDADE E RESPONSABILIDADE SOCIAL: ORIGENS, MOTIVAÇÕES, CRÍTICAS E ASPECTOS PRÁTICOS.
}

\section{COMPANY, SUSTAINABILITY AND SOCIAL RESPONSIBILITY: ORIGINS, MOTIVATIONS, CRITICAL AND PRACTICAL ASPECTS.}

\author{
${ }^{1}$ Mariana Ribeiro Santiago \\ ${ }^{2}$ Pedro Antonio de Oliveira Machado
}

\section{RESUMO}

O presente trabalho analisa a sustentabilidade e seus aspectos históricos, o surgimento da preocupação mundial sobre o tema, com o desenvolvimento econômico sustentável e suas principais iniciativas, a partir do efetivo envolvimento dos Estados nas discussões para a busca de consenso sobre as a qualidade de vida no planeta, da racionalidade na exploração dos recursos naturais e da preocupação com as gerações futuras. Abordase também o contexto da responsabilidade social (empresarial), iniciando pelo seu aspecto histórico, para na sequência analisar o seu papel enquanto instrumento de combate ao problema da desigualdade social e pobreza, discorrendo-se sobre a possibilidade de atuação estatal enquanto indutora de comportamentos empresariais nesta temática, descrevendo a experiência concreta, revelada na atuação do Ministério Público Federal, através de premiado Projeto que ficou conhecido como Municípios Verdes/Carne Legal.

Palavras-chave: Desenvolvimento sustentável, Responsabilidade social, Consumo

\footnotetext{
${ }^{1}$ Doutora em Direito pela Pontifícia Universidade Católica de São Paulo - PUC, São Paulo (Brasil). Professora de Direito Civil pela Universidade de Marília - UNIMAR, São Paulo (Brasil).

E-mail: mariana@nbsadvogados.com.br

${ }^{2}$ Bacharel em Direito pela Instituição Toledo de Ensino - ITE, São Paulo (Brasil). Procurador pela Procuradoria Regional dos Direitos do Cidadão - PRDC, São Paulo (Brasil). E-mail: pedromachado@mpf.mp.br
} 


\begin{abstract}
The present paper analyzes the sustainability and its historical aspects, the emergence of global concern about the subject, with sustainable economic development and its major initiatives, from the effective involvement of the States in the discussions in the search for consensus in the quality of life on the planet, rationality in the exploitation of natural resources and concern for future generations. We research also the context of social responsibility (business), starting at historical aspect to following analyze its inter- relationship as an instrument to combat the problem of social inequality and poverty, was discoursing on the possibility of state action while inducing corporate behavior on this theme, describing the concrete experience revealed in the actions of the Federal Public Ministry, through award-winning design that became known as "Green Cities / Meat Legal".
\end{abstract}

Keywords: Sustainable development, Social responsibility, Consumption 


\section{INTRODUÇÃO.}

A temática da sustentabilidade, como alternativa para a preservação do planeta, e de sua condição de habitabilidade, mormente para as futuras gerações, está na pauta do dia, abrangendo aspectos como o acesso e abastecimento de água potável, infraestrutura e saneamento, aumento da concentração de dióxido de carbono na atmosfera, atividades agropastoris cada vez mais intensivas, com avanço do desmatamento e extinção de vastas porções de floresta natural, com várias espécies de anfíbios, mamíferos e aves ameaçadas de extinção, destruição de abrigos naturais, recifes e manguezais, imprescindíveis principalmente para a reprodução e manutenção da vida marinha.

Por outro lado, o formato de produção e consumo, exercício primordial e que haveria de estar no foco das discussões sobre desenvolvimento sustentável, precisa ser repensado, pois as reflexões nesta seara têm se concentrado mais intensamente sobre a melhoria da técnica de industrialização, olvidando ou deixando em segundo plano a urgência de se debater sobre a mudança de paradigma acerca do vigente sistema capitalista, sua forma de exploração dos recursos naturais e as respectivas relações de consumo.

Assim, buscaremos abordar, nesta oportunidade, a origem e as principais iniciativas e discussões que levaram à construção da ideia de sustentabilidade ou desenvolvimento sustentável, enquanto preocupação mundial, capitaneada pela Organização das Nações Unidas (ONU), com o intenso envolvimento da comunidade internacional.

Sob a perspectiva do contexto histórico, mostra-se salutar a análise sobre o surgimento da ideia de responsabilidade social (empresarial ou corporativa), bem como as possibilidades de sua influência para o enfrentamento dos desafios envolvendo a exploração racional e consciente dos recursos naturais, com respeito ao meio ambiente e ao desenvolvimento econômico, que esteja antenado também com os interesses dos consumidores, fornecedores, empregados, comunidade etc (os stakeholders).

No mais, de forma ilustrativa, abordaremos o caso de responsabilidade social estimulada pelo poder público decorrente de atuação institucional do Ministério Público Federal no Estado do Pará, conhecido como "Projeto Municípios Verdes/Carne Legal”, que produziu resultados significativos, para a implementação de exploração mais racional e sustentável no ramo de atividades agropecuárias na região amazônica, propiciando ainda a 
redução do desmatamento, a regularização fundiária, o combate à grilagem de terras públicas e territórios indígenas, a redução do trabalho escravo no campo etc.

A aludida iniciativa, que recebeu, dentre outros, o "Prêmio Innovare", no ano de 2012, cabe ressaltar, é de suma importância, considerado que Brasil lidera o ranking de maior exportador de carne bovina do mundo desde $2008^{1}$.

O panorama ora noticiado justifica o estudo aprofundado da responsabilidade social da empresa, intimamente ligada aos princípios da função social e da solidariedade social, dentro da perspectiva de uma sociedade de consumo, com o objetivo oferecer subsídios para se balizar a atividade empresarial, verificando opções de negócios mais equilibradas e responsáveis, em sintonia com as exigências da pós-modernidade.

Para a obtenção dos resultados almejados pelo trabalho, utilizamos a pesquisa bibliográfica e documental. O método de abordagem seguido foi o dialético jurídico, abrangendo o fenômeno, fato concreto e a teoria, de forma simultânea, buscando o resultado com o confronto entre os dois.

\section{ECODESENVOLVIMENTO E DESENVOLVIMENTO SUSTENTÁVEL, NO PARADIGMA DA MODERNIDADE LÍQUIDA.}

\subsection{SUSTENTABILIDADE: ORIGEM HISTÓRICA.}

Pode-se afirmar que o embrião do que hoje se conhece como desenvolvimento sustentável, foi a expressão ecodesenvolvimento, cunhada por Maurice Strong, Secretário da Conferência de Estocolmo, evento realizado pela Organização das Nações Unidas (ONU) entre os dias 5 a 16 de junho de 1972, na capital da Suécia, conforme informa Gilberto Montibeller Filho (MONTIBELLER FILHO, 1992, pp.331-342), em artigo científico intitulado "Ecodesenvolvimento e desenvolvimento sustentável". Este evento realizado pela Organização das Nações Unidas (ONU) entre os dias 5 a 16 de junho de 1972, na capital da Suécia, pode ser identificado como marco inicial da preocupação mundial com a preservação do meio ambiente, tendo reunido 113 países e 250 organizações não governamentais ${ }^{2}$.

$\mathrm{Na}$ sequência, três iniciativas internacionais merecem destaque, sendo a primeira a criação pela ONU da Comissão Mundial sobre Meio Ambiente e Desenvolvimento, em 1983,

\footnotetext{
${ }^{1}$ BRASIL. MINISTERIO DA AGRICULTURA. . Homepage. 2015. Página Inicial> Animal. Disponível em: <http://www.agricultura.gov.br/animal>. Acesso em: 11 jun. 2015.

${ }^{2}$ BRASIL. PORTAL BRASIL MEIO AMBIENTE. (Org.). Acordos globais: Conferência das Nações Unidas sobre o Meio Ambiente Humano - 1972. 2012. Disponível em: <http://www.brasil.gov.br/meio- ambiente/2012/01/acordosglobais>. Acesso em: 10 maio 2015.
} 
que deveria estudar e estruturar propostas para enfrentar os problemas dos impactos das atividades econômicas no meio ambiente. Esta Comissão, presidida pela primeira-ministra da Noruega Gro Harlem Brundtland, construiu então o relatório denominado "Nosso Futuro Comum" (Our Common Future), também chamado de Relatório Brundtland, que cunha termo “desenvolvimento sustentável”, empregado até os dias atuais.

O Relatório Brundtland trabalha com a ideia de que desenvolvimento sustentável é aquele que satisfaz as necessidades do presente sem comprometer a capacidade das gerações futuras satisfazerem as suas próprias necessidades, impondo ainda dois conceitos-chave: o de necessidades, em particular as necessidades essenciais dos pobres do mundo, a que deve ser dada prioridade absoluta; e o reconhecimento da existência de limitações que o estágio da tecnologia e da organização social impõem ao meio ambiente, impedindo-o de atender às necessidades presentes e futuras.

Prosseguindo-se nesta linha histórica tem-se a Conferência das Nações Unidas sobre o Meio Ambiente e Desenvolvimento (CNUMAD), realizada em junho de 1992, no Rio de Janeiro, RIO+20, ECO-92, que reuniu delegações de 178 (cento e setenta e oito) países e trouxe para a cidade 114 (cento e quatorze) Chefes de Estado ou de Governo, com seu evento conhecido como a Cúpula da Terra, reunião das delegações oficiais dos países participantes, no âmbito da qual decisões diplomáticas e acordos internacionais foram construídos (OLIVEIRA, 2012).

Dez anos após, pela Resolução 55/199 da Assembleia Geral das Nações Unidas, intitulada "Revisão decenal do progresso alcançado na implementação dos resultados da Conferência das Nações Unidas sobre Meio Ambiente e Desenvolvimento", foi convocada a Cúpula Mundial sobre Desenvolvimento Sustentável em agosto 2002 (LAGO, 2006, pp. 87110), conhecida como Cúpula de Joanesburgo (cidade sul-africana onde ocorreu o evento) ou Rio+10 (alusão ao decêndio transcorrido desde a ECO-92, na cidade do Rio de Janeiro).

Sabido que não existe classificação certa ou errada, mas apenas que umas podem se mostrar mais úteis do que outras, conforme a abordagem pretendida pela pesquisa, é possível a partir de tais documentos internacionais identificar, sinteticamente, três dimensões de sustentabilidade: social, econômica e ambiental.

Em apertada síntese, a sustentabilidade social revela-se por meio de iniciativas voltadas a melhorar a qualidade de vida da população, buscar o equilíbrio e o bem-estar da sociedade, auxiliando os membros dessa sociedade que enfrentam condições desfavoráveis. Já 
a sustentabilidade econômica está ligada à preocupação de distribuição intertemporal de recursos naturais finitos, o que pressupõe a definição de limites para o seu uso em escala comercial (OLIVEIRA, 2010, pp. 14-21). Por fim, a sustentabilidade ambiental busca a difícil harmonia entre a exploração dos recursos naturais e manutenção do equilíbrio do meio ambiente, de forma a atender as necessidades do presente, sem comprometer a qualidade de vida imediata, além de preservar o planeta para as futuras gerações.

\subsection{SUSTENTABILIDADE E CONSUMO: VISÃO CRÍTICA.}

Em verdade, as três dimensões da sustentabilidade estão intimamente ligadas, sendo certo que ausência de atenção a qualquer delas acarretará, cedo ou tarde, repercussões perigosas sobre a atividade econômica e a estrutura do mercado capitalista, modelo hodiernamente adotado em escala mundial que, apesar dos alertas e discussões internacionais, com envolvimento de Estados e instituições não governamentais, ainda produz um ritmo e formato de consumo que é altamente predatório e destruidor dos recursos naturais, com preocupação, até o momento, insuficiente no que se refere à manutenção da qualidade de vida no planeta e à busca da distribuição de renda, igualdade e justiça social.

Nesse ponto, Édis Milaré (2009, p. 72) após afirmar que a sustentabilidade dos recursos naturais está ligada à sua durabilidade e disponibilidade, bem como alertar que essa sustentabilidade está relacionada diretamente à forma como são eles explorados e usados, cita o exemplo da água, anotando que conquanto o ciclo hidrológico seja fechado, de modo que a quantidade dos recursos hídricos é sempre a mesma no planeta, a sua escassez vem sendo notada em razão do aumento da demanda e multiplicidade do uso, o que piora paulatinamente a sua qualidade e exige tratamentos cada vez mais custosos para sua utilização.

Este sensível tema da sustentabilidade suscita reflexões profundas. Mário Sérgio Cortella (2013, p.55), em seu livro "Pensar bem nos faz bem!", noticia e traz as seguintes considerações sobre interessante e bem-humorada frase do escritor Millor Fernandes:

\footnotetext{
O escritor Millor Fernandes, estupendo brasileiro, que faleceu em março de 2012, nos legou uma frase que eu considero de uma inteligência especial: 'Se você não tem dúvidas, é porque está mal-informado'. Olha que coisa boa. Há várias pessoas que acham que o conhecimento é a ausência de dúvida, a completa certeza, e não é. Aliás, um conhecimento que fosse pura certeza ficaria estagnado e teríamos um nível de redundância muito forte.

É claro que eu não posso ser alguém que só tem dúvidas, porque aí não ajo. Mas não ter dúvidas sinaliza falta de inteligência. Quando se pensa nas várias fontes de informação que precisamos ter no nosso dia a dia, é necessário ter lugar também a dúvida.

Não a dúvida que se coloca como mera suspeita, mas uma dúvida metódica [...]".
} 
Sob o background dessa advertência de Millor Fernandes, imprescindível atentar para a visão crítica à construção da ideia de desenvolvimento sustentável (DS), da Comissão Mundial sobre Meio Ambiente e Desenvolvimento (CMMAD), apresentada por Dias e Tostes (2010) com arrimo na linha de entendimento do antropólogo Guillermo Foladori, do geógrafo Milton Santos e do sociólogo Immanuel Wallerstein:

\footnotetext{
A institucionalização do conceito de DS se deu, sobretudo, com base em uma interpretação feita pela teoria econômica neoclássica, que praticamente exclui qualquer correlação entre as relações sociais de produção e as origens da crise ambiental. Muitas políticas envolvendo DS limitam-se à inclusão do termo "sustentável" em projetos que francamente não propõem qualquer alteração substancial em modelos de desenvolvimento.

$[\ldots]$

A CMMAD, ao apostar no avanço tecnológico como um dos elementos capazes de promover o DS, acredita que o maior problema está na relação sociedade-natureza e não na relação do ser humano com seus congêneres.

[...]

Em verdade, não há uma humanidade que se defronta em bloco com uma base finita de materiais. Antes, há um confronto no interior da humanidade, entre classes sociais.

$[\ldots]$

Dessa forma, o processo produtivo capitalista é pouco questionado pelos apologistas do DS. Quando muito, questiona-se a industrialização, ou seja, a técnica.

[...]

Conclui-se, assim, que a classe capitalista encontrou no DS um instrumento de defesa do seu status quo, na medida em que essa proposta de desenvolvimento praticamente não questiona as relações sociais de produção, limitando-se à crítica das relações técnicas, o que é menos problemático para o capital.
}

Outrossim, não se desconhece que sob a perspectiva de soft law pode-se até vislumbrar uma preocupação dos Estados, no âmbito das discussões em eventos oficiais internacionais, quanto à necessidade de repensar os modelos de produção e consumo adotados, como estampa o Princípio $n^{\circ}$ 8, da Declaração do Rio sobre Meio Ambiente e Desenvolvimento ${ }^{3}$ :

Para alcançar o desenvolvimento sustentável e uma qualidade de vida mais elevada
para todos, os Estados devem reduzir e eliminar os padróes insustentáveis de
produção e consumo, e promover políticas demográficas adequadas ${ }^{4}$

Todavia, considerado o valor limitado e juridicamente não obrigatório da referida declaração de princípios, a crítica realmente é pertinente, pois afigura-se inegável a

${ }^{3}$ Documento resultante da Conferência das Nações Unidas sobre o Meio Ambiente e Desenvolvimento (CNUMAD), realizada em junho de 1992, no Rio de Janeiro, RIO+20, ECO-92.

4 ORGANIZAÇÃO DAS NAÇÕES UNIDAS (Org.). Declaração do Rio sobre Meio Ambiente e Desenvolvimento. 1992. Disponível em: 〈http://www.onu.org.br/rio20/img/2012/01/rio92.pdf〉. Acesso em: 27 maio 
necessidade de modificação substancial nos modelos de desenvolvimento, ancorados no processo produtivo capitalista vigente, que produz desigualdade social e caminha a passos largos para tornar o planeta um local inóspito, conforme vaticina José Eli da Veiga (2005, pp. 4-5), trazendo observações que impõem reflexões inadiáveis sobre a necessidade de revisão do modelo econômico capitalista, assim como das atuais relações de consumo dele derivadas:

\begin{abstract}
Até hoje, não existiu diferença entre industrialismo e desenvolvimento.
[...]

Percebeu-se que haveria drástica quebra de resiliência ecossistêmica do planeta se muitos povos pudessem gozar dos atuais padrões de vida norte-americano, japonês ou europeu. Taxas de crescimento econômico semelhantes às da 'Era de Ouro' (1948-1973) certamente teriam conseqüências irreversíveis e catastróficas para o ambiente natural do planeta, incluindo a humanidade que é parte dele. Não destruiria a Terra, nem a tornaria inabitável, mas certamente mudaria o padrão de vida na biosfera, e poderia muito bem torná-la inabitável para a espécie humana.

É essa a contradição que está na base da noção de desenvolvimento sustentável. Procura-se uma solução de compromisso entre o industrialismo ainda exigido pela periferia e o pós-industrialismo já inaugurado no centro. Sejam quais forem os termos desse compromisso, uma coisa é certa: a velha utopia industrialista não é mais sustentável.
\end{abstract}

Nessa linha, mas de forma aguda e perspicaz, oferece Bauman (2007, p. 48) interessante visão crítica do funcionamento do sistema capitalista e da sociedade de consumo:

\begin{abstract}
O mercado não sobreviveria caso os consumidores se apegassem às coisas. Para a sua própria sobrevivência, não pode tolerar clientes comprometidos e leais ou que apenas se mantenham numa trajetória consistente e coesa que resista a desvios e evite saídas colaterais. Além, é claro, daqueles que estão comprometidos a comprar e leais às trajetórias que conduzem aos shopping centers. O mercado sofreria um golpe mortal se o status dos indivíduos parecesse seguro, se suas realizações e propriedades fossem garantidas, se seus projetos se tornassem finitos, e se o fim de seus esforços por uma ascensão fosse plausível. A arte do marketing está focalizada em evitar a limitação das opções e a realização dos desejos. Contrariamente às aparências e às declarações oficiais, assim como ao senso comum que é fiel a ambas, a ênfase aqui recai não na estimulação de novos desejos, mas na extinção dos "antigos" (leia-se: os de um minuto atrás), a fim de limpar o terreno para novas incursões ao shopping.
\end{abstract}

Recorrendo-se outra vez a Milaré (2009, pp. 80-81), cabe, por relevante, inserir na reflexão a diferença entre consumo e consumismo, anotando que o primeiro diz respeito ao necessário indispensável enquanto o segundo reflete o supérfluo perdulário e decorre de uma mentalidade apegada a hábitos mórbidos, por vezes compulsivos, pois o consumista é um iludido ou auto-iludido, sendo certo, no entanto, que faz parte da grande maioria que cresce assustadoramente, notadamente nos países pobres ou em desenvolvimento, e cuja postura indubitavelmente traz riscos ao meio ambiente $\mathrm{e}$ à ideia de sustentabilidade. 
De qualquer forma, não deixando de reconhecer a sua relevância, imperioso não eleger este problema da dicotomia entre consumo e consumismo como fator primordial, ou decisivo, na agenda da sustentabilidade, pois o método de produção e a visão que se adota acerca do uso dos recursos naturais, as estruturas do capitalismo, além do comportamento dos agentes de mercado e a forma como a sociedade se relaciona com o consumo, não podem deixar de estar no centro das preocupações para a busca da sustentabilidade.

Fábio Konder Comparato (2015, pp. 441-442) noticia estudo realizado em 2005, sob a coordenação da ONU, intitulado Avaliação Ecossistêmica do Milênio, com a participação de 1.350 cientistas, de 95 países, que traz constatações alarmantes, revelando, por exemplo, que mais de um bilhão de pessoas não têm acesso ao abastecimento de água potável e mais de três bilhões não dispõem de infraestrutura e saneamento; ademais a concentração de dióxido de carbono cresceu $32 \%$ desde ao ano de 1750, com mais terras sendo convertidas para atividades agropastoris após o ano de 1945 do que durante os séculos XVII e XIX, além do que, entre 10 e $30 \%$ de todas as espécies de anfíbios, mamíferos e aves estão ameaçadas de extinção, havendo ainda destruição de $20 \%$ dos recifes e $30 \%$ dos manguezais existentes no mundo.

Nesse sentido, constatamos que a tudo precisa se estar atento para que a concepção de desenvolvimento sustentável, mormente sobre a influência do poder econômico, não se transforme no "progresso do atraso" ou em uma "verdade fictícia", o que significa repensar o papel da empresa na contemporaneidade e sua responsabilidade perante a sociedade.

\section{FUNÇÃO SOLIDÁRIA DA EMPRESA NO ORDENAMENTO JURÍDICO NACIONAL.}

No contexto da sociedade de consumo, as empresas estimulam o jogo das diferenças, pregando que estas precisam ser reconhecidas e legitimadas socialmente, operando, assim, na esfera dos estilos de vida, potencializando o fenômeno do consumismo (FEATHERSTONE, 1995, p. 124).

Se a lógica da mercadoria predomina, ao regular a cultura inteira, desde os processos de trabalho à questão da sexualidade, isso requer uma atividade socialmente muito mais responsável por parte da empresa. Pode-se afirmar, nessa linha, que a atividade empresarial 
que não é socialmente responsável, no contexto da sociedade de consumo, pode induzir ou contribuir para que se instaure uma era da alienação radical.

A pesquisadora e consultora da Fipe ${ }^{5}$, Fernanda Gabriela Borger (2013), esclarecendo que responsabilidade social é um conceito que retroage à década de 1950, nos Estados Unidos e na Europa, registra que:

\begin{abstract}
A ideia de sustentabilidade, ou desenvolvimento sustentável, começou em grande parte com a preocupação ambiental, que acabou por envolver as dimensões econômica e social e, a partir dos anos 1990, passou a incluir a responsabilidade social empresarial. A evolução do conceito de responsabilidade social é diferente. Sua origem está nas questões éticas que envolvem a relação entre empresas e sociedade e na filantropia empresarial.
\end{abstract}

Sobre o tema, nos Estados Unidos, foi publicado em 1953 por Howard R. Bowen (professor de economia do "Williams College") importante estudo, consolidado na obra "Social Responsibilities of the Businessman", traduzido no Brasil por Octávio Alves Velho, sob o título "Responsabilidades Sociais do Homem de Negócios". E, já na introdução de referida obra, esclarecendo que está a tratar das responsabilidades sociais das grandes empresas dos Estados Unidos, afirma Bowen (1957, pp. 11-15) que o homem de negócios não chega, por vezes, a perceber completamente a conexão entre suas decisões empresariais e o bem-estar público, alertando que não só o governo, mas também o comércio é, fundamentalmente, "do povo, pelo povo, e para o povo", de modo que a liberdade de escolha é outorgada ao homem de negócios porque o povo julga desejável tal descentralização.

Mister, outrossim, observar que tal publicação surge no contexto da guerra fria, período que vai de 1945, com o final da segunda guerra mundial, até o ano de 1991, marcado por disputas entre os dois grandes blocos políticos e econômicos mundiais, os Estados Unidos e a União Soviética, não só sob o aspecto político, militar, tecnológico, mas também econômico, social e ideológico. E, nessa contenda, o primeiro a defender o capitalismo, o direito à propriedade privada e a livre iniciativa, enquanto a segunda a agasalhar e patrocinar o socialismo, a extinção da propriedade privada, a igualdade econômica e o fortalecimento Estatal para garantir as necessidades básicas dos cidadãos.

Ante tal quadro é possível extrair, dos apontamentos lançados por Bowen (1957, pp. 66-67), que estava por trás da ideia de responsabilidade social, primordialmente, a preocupação quanto à defesa e manutenção do regime e da ideologia econômica e social do capitalismo. Isso porque, após pontuar que o liberalismo econômico puro não se mostrou

\footnotetext{
${ }^{5}$ Fundação Instituto de Pesquisas Econômicas.
} 
adequado aos anseios da sociedade, conduzindo ao declínio do "laissez-faire", tanto teoricamente como na prática, gerando nos Estados Unidos uma mistura de livre-iniciativa e controle social, na forma de "capitalismo beneficente" (no original: welfare capitalism) ou "economia mista", revela ele que:

\begin{abstract}
O ponto importante que um número cada vez maior de homens de negócios está percebendo, é que o clima da opinião pública e das forças políticas em cujo âmbito funcionam as empresas de hoje, difere drasticamente do que há cinqüenta ou mesmo vinte e cinco anos atrás. A experiência, em nossa terra, de depressão, guerra e inflação, e a observação, no estrangeiro, do socialismo e do comunismo, modificaram os critérios de julgamento das atividades dos negócios privados [...]

Já vão longe os dias de rapina, de exploração de seres humanos e de chicana financeira pelos homens de negócios. E os dias em que o lucro máximo era o único critério do sucesso comercial, também estão desaparecendo rapidamente. Estamos entrando em uma era em que os negócios privados serão julgados exclusivamente em função de sua contribuição concreta para o bem-estar coletivo. Os mais destacados pensadores do mundo dos negócios compreendem isso claramente. Para êles, por conseguinte, a aceitação de obrigações para com os trabalhadores, consumidores e público em geral, é um requisito para a sobrevivência do sistema de livre emprêsa. Por isso, mesmo que se tomem as conveniências dos acionistas como único alvo dos negócios, torna-se mandatória para a administração a solicitude com objetivos sociais mais vastos.
\end{abstract}

Ante tais constatações de Bowen, que possibilitam uma reflexão para situar o tema sob a sua real perspectiva, prossegue-se para anotar que a sustentabilidade está ligada a uma visão macro, envolvendo não só, mas notadamente, aspectos econômicos, políticos, sociais, culturais e ambientais acerca do problema da exploração de recursos naturais no planeta. Outrossim, a responsabilidade social empresarial traduz a busca da harmonização da exploração econômica, com o meio ambiente e com os aspectos sociais que circundam a atividade econômica imediata das empresas, que nesta perspectiva devem conferir respeito aos parceiros, consumidores, fornecedores, empregados etc. (os stakeholders), levando em conta, no mais, os anseios e necessidades da comunidade local na qual está inserida.

Conforme pontua Eduardo Tomasevicius Filho (2003, pp. 33-50), a responsabilidade social sob tal prisma apresenta-se através da "[...] integração voluntária de preocupações sociais e ambientais por parte das empresas nas suas operações e na sua interação com a comunidade [...]", sendo "[...] uma forma de levar outras instituições a colaborar com o Estado na busca de justiça social, ao invés de ficar esperando que o Estado tome todas as providências nessas áreas".

Assim, a responsabilidade social, data venia, não se identifica com simples filantropia, com a mera ajuda material, caracterizada com certo proselitismo, mas sim com um atuar das empresas efetivamente comprometido e antenado com a comunidade, com os impactos negativos que sua atividade econômica possa produzir, influenciando tanto o seu espaço 
social mais próximo (minimizando ao máximo a poluição, ofertando melhores condições para seus trabalhadores, programas de economia de água e energia, programas de compliance etc.), como também o remoto, no que toca às consequências da inserção de seus produtos e serviços no mercado (embalagens biodegradáveis, diminuição de sódio e corante nos produtos alimentícios, abaixo dos índices autorizados pelo Poder Público etc.).

O Pacto Internacional sobre Direitos Econômicos, Sociais e Culturais, assim como o Pacto Internacional sobre Direitos Civis e Políticos, adotados pela XXI Sessão da Assembleia Geral das Nações Unidas, em dezembro de 1966, foram incorporados ao direito pátrio com a aprovação através do Decreto Legislativo $\mathrm{n}^{\circ} 116$, de 12 de dezembro de 1991 e posterior promulgação por meio do Decreto n ${ }^{\circ} 592$, de 6 de julho de 1992.

Comparato (2015, pp. 350-351), ao comentar tais instrumentos internacionais, afirma que o primeiro deles, ao contrário do segundo, tem como elemento comum não a defesa de indivíduos ou grupos sociais contra privilégios privados ou abuso do poder estatal, mas sim a proteção das classes ou grupos sociais desfavorecidos contra a dominação socioeconômica exercida pela minoria rica e poderosa, alertando, contudo, que de ambos os pactos colhe-se a diretriz de que a liberdade individual é ilusória sem um mínimo de igualdade social, lembrando que o princípio da solidariedade é o fecho da abóbada de todo o sistema de direitos humanos, asseverando no mais que para a fruição das liberdades civis exige-se a abstenção estatal, mas para os direitos econômicos a antijuridicidade está na inércia estatal em limitar ou controlar o poder econômico privado.

A solidariedade social ingressa no sistema jurídico nacional materializada no art. $3^{\circ}, \mathrm{I}$, da Constituição Federal, como marca do Estado democrático de direito, estimulando em cada indivíduo consciência perceptiva do ambiente social, pelo que pode ser considerada como um novo paradigma para o direito, no qual Estado e indivíduos assumem uma aliança, de caráter absolutamente democrático, visando incrementar direitos básicos destes, promoção de políticas de erradicação da pobreza e de redução das desigualdades (CARDOSO, 2010, pp. $109,116,122$ e 151).

Comentando o art. $3^{\circ}$, I, da Constituição brasileira, José Afonso da Silva (2009, pp. 46-47) assevera:

O que a Constituição quer, com esse objetivo fundamental, é que a República Federativa do Brasil construa uma ordem de homens livres, em que a justiça distributiva e retributiva seja um fator de dignificação da pessoa e em que o sentimento de responsabilidade e apoio recíprocos solidifique a ideia de comunidade fundada no bem comum. Surge aí o signo do Estado democrático de direito, voltado à realização da justiça social, tanto quanto a fórmula liberdade igualdade e 
fraternidade o fora no Estado liberal proveniente da Revolução Francesa.

Ao tentar precisar o alcance da palavra solidariedade, Paulo Luiz Netto Lôbo (2009, p. 81) afirma que esta,

como categoria ética e moral que se projetou para o mundo jurídico, significa um vínculo de sentimento racionalmente guiado, limitado e auto-determinado que impõe a cada pessoa deveres de cooperação, assistência, amparo, ajuda e cuidado em relação às outras. A solidariedade cresce de importância na medida em que permite a tomada de consciência da interdependência social.

A solidariedade social realiza-se, então, como um ato complexo, no qual concorrem o Poder Público e a própria sociedade, apontando a Constituição Federal as diretrizes ideológicas, políticas e jurídicas para sua otimização e implementação, ao acolher os princípios da dignidade humana e do pluralismo social e político (DINIZ, 2007, p. 173).

O discurso da solidariedade, dentro de um quadro democrático, implica admitir direitos e deveres nas relações interindividuais, como cooperação e respeito, exigindo uma postura não só do Estado, mas também de cada cidadão em relação a todos os demais, o que vai muito além dos limites impostos às empresas pelo instrumento da função social.

A função social obriga os contratantes a não se afastarem das "expectativas sociais" referentes a um dado negócio, não se desviando para propósitos inúteis ou contrários à coletividade, sob pena de se observar a interferência estatal na readequação do negócio. Impõe, assim, às partes, uma postura negativa de não desrespeitar a sociedade.

A seu turno, o princípio da solidariedade, que sustenta a função solidária da empresa, possui uma conotação diversa, pois agrega uma ideia de que se deve também colaborar, por meio do negócio, para o desenvolvimento da sociedade, numa perspectiva de auxílio às pessoas, de uma forma positiva, inclusive sob o ângulo das gerações futuras. A função solidária da empresa é aquela que traz uma contribuição valorosa para o desenvolvimento social.

A compreensão da dinâmica da solidariedade resta sobremaneira facilitada se utilizarmos o recurso da exemplificação. As atividades de construção civil mostram-se bastante elucidativos nesse ponto.

Existe, atualmente, uma série de normas que as edificações públicas e privadas devem seguir, sob pena de intervenção do Poder Público, como aquelas estabelecidas nos Códigos de obras municipais. Respeitando essas normas, as empresas estão cumprindo sua função social, deixando de gerar riscos e prejuízos para toda a sociedade. 
Essas obras, todavia, podem ir além de simplesmente cumprir as imposições legais e não aviltar a comunidade. Elas podem colaborar, voluntariamente, com a preservação do meio ambiente e, assim, auxiliar o desenvolvimento social, otimizando a qualidade de vida das pessoas, atuando, de forma solidária, além das exigências legais, como no caso das chamadas "obras verdes".

As construções verdes têm se mostrado uma tendência na arquitetura moderna, a despeito do acréscimo que representa em matéria de custos, seguindo os preceitos da sustentabilidade, através da adoção de técnicas como a reutilização de águas cinzas e pluviais, uso de energia solar, materiais ecoeficientes, aproveitamento de ventilação e iluminação naturais etc.

Não existe, assim, uma norma que imponha aos contratantes, nesses casos, a adoção das mais avançadas técnicas de sustentabilidade. Todavia, há um reconhecimento de tais iniciativas por meio da certificação de sustentabilidade conferida por alguns órgãos, em virtude das características da obra. A certificação mais conhecida no Brasil é a LEED (Leadership in Energy and Environmental Design), concebida e concedida pela organização não governamental americana U.S. Green Building Council.

O problema é que, como anota Eros Grau (2006, pp. 208-209), o poder econômico não apenas é um elemento da realidade, como está ainda institucionalizado constitucionalmente, pois o $\S 4^{\circ}$ do art. 173, da C.F. refere-se à repressão ao abuso do poder econômico, daí porque o poder econômico é a regra e não a exceção, frustrada assim a suposição de que o mercado estaria organizado naturalmente em função do consumidor.

Aliás, acrescente-se, que o citado dispositivo constitucional determina a repressão ao (abuso) do poder econômico que vise à dominação dos mercados, à eliminação da concorrência e ao aumento arbitrário dos lucros, ou seja, muito mais voltado para a manutenção da higidez da estrutura do mercado, do que para a proteção do consumidor.

Outrossim, é preciso não olvidar, conforme anota o documento produzido pela Comissão Econômica para a América Latina e o Caribe (CEPAL), "Panorama Social da América Latina, Síntese, 2014"6, que na América Latina o panorama persistente é o da desigualdade na distribuição dos recursos e no exercício dos direitos, com a característica de

${ }^{6}$ DIVISÃO DE DESENVOLVIMENTO SOCIAL E A DIVISÃO DE ESTATÍSTICAS DA COMISSÃO ECONÔMICA PARA A AMÉRICA LATINA E O CARIBE (Org.). Panorama Social da América Latina. 2014. CEPAL. 2015. 
que mesmo não sendo a região mais pobre do mundo, se destaca por ser a mais iníqua, o que representa um obstáculo para o bem-estar atual e o desenvolvimento futuro de suas sociedades e economias.

Segundo o mesmo documento, para o Brasil, no ano de 2013, apurou-se uma taxa de pobreza de $18 \%$ da população e, de indigência ou pobreza extrema, de $5,9 \%$ da população. É bem verdade que tais índices vêm diminuindo desde 2005, mas entre 2012 e 2013 foi muito pequena a variação, com uma queda da taxa de pobreza de 0,6 ponto percentual, mas com um incremento da taxa de indigência de 0,5 ponto percentual.

De rigor ainda o registro do lançamento, no final do ano de 2010, da Norma Internacional ISO 26000, que estabelece diretrizes sobre Responsabilidade Social. Tal documento, conquanto não tenha caráter certificador, mas apenas de diretrizes de uso voluntário, foi elaborado por iniciativa da Organização Internacional de Normalização (ISO), sob a presidência da Associação Brasileira de Normas Técnicas (ABNT) e o Instituto Sueco de Normalização (SIS $)^{7}$. Elenca princípios e vetores éticos de atuação empresarial, assim enunciados: accountability (responsabilização pelos efeitos de suas ações e decisões), transparência, comportamento ético, respeito pelos interesses das partes interessadas (stakeholders), pelo Estado de direito, pelas normas internacionais de comportamento e pelos direitos humanos.

\section{RESPONSABILIDADE SOCIAL ESTIMULADA: "PROJETO CARNE LEGAL".}

$\mathrm{Na}$ linha da solidariedade social, em diferentes partes do mundo, uma outra espécie de economia, gestada a partir de iniciativas, sobretudo de natureza cooperativista e associativista, oriundas da sociedade civil e dos meios populares, já é realidade. Mostra-se sob diferentes configurações: criação coletiva do próprio circuito de produção e consumo, alimentando cadeias socioprodutivas autônomas e, em alguns casos, não-monetarizadas, ou diferentes tipos de parcerias com os poderes públicos. É o que se chama de economia colaborativa-solidária. Como exemplos, projetam-se os bancos populares, clubes de trocas e as cooperativas sociais (FRANÇA FILHO, 2004, p. 15).

Nesse passo, algumas espécies de contrato em particular se mostram em exata sintonia com os preceitos da economia solidária e do consumo colaborativo, como a troca e a locação de coisas, concretizando o que se pode chamar de função solidária do contrato de consumo.

${ }^{7}$ BRASIL. ASSOCIAÇÃO BRASILEIRA DE NORMAS TÉCNICAS. (Comp.). ISO 26000:2010. 2010. Disponível em: <http://www.inmetro.gov.br/qualidade/responsabilidade_social/iso26000.asp>. Acesso em: 11 jun. 
Já conseguimos visualizar que fazemos, atualmente, parte de um movimento maior, e esta consciência da dinâmica e da finalidade da comunidade acaba por estimular o surgimento de novas economias e inovações, o que contribui para a implementação das medidas de sustentabilidade (BOTSMAN e ROGERS, 2011, p. 176).

Nesse prisma, ao tratar do tema da sustentabilidade, Juarez Freitas (2012, p. 41) ensina que

\begin{abstract}
trata-se do princípio constitucional que determina, com eficácia direta e imediata, a responsabilidade do Estado e da sociedade pela concretização solidária do desenvolvimento matéria e imaterial, socialmente inclusivo, durável e equânime, ambientalmente limpo, inovador, ético e eficiente, no intuito de assegurar, preferencialmente de modo preventivo e precavido, no presente e no futuro, o direito ao bem-estar.
\end{abstract}

E continua o referido autor (FREITAS, 2012, pp. 29 e 31):

\begin{abstract}
a sustentabilidade não pode ser considerada um tema efêmero ou de ocasião, mas prova viva da emergência de uma racionalidade dialógica, interdisciplinar, criativa, antecipatória, medidora de consequências e aberta. (...) As grandes questões ambientais do nosso tempo (a saber, o aquecimento global, a poluição letal do ar e das águas, a insegurança alimentar, o exaurimento nítido dos recursos naturais, o desmatamento criminoso e a degradação disseminada do solo, só para citar algumas) devem ser entendidas como questões naturais, sociais e econômicas, simultaneamente, motivo pelo qual só podem ser equacionadas mediante uma abordagem integrada, objetiva, fortemente empírica e, numa palavra, sistemática.
\end{abstract}

Se analisarmos retrospectivamente para as invenções simples e úteis da modernidade, surge a questão: qual foi o prejuízo? Esses produtos foram aceitos na sociedade como símbolo de progresso e, de fato, apresentam benefícios. A questão se torna mais complexa, todavia, quando nos perguntamos quando e como a aceitação cultural da descartabilidade se ampliou para limites fora da razoabilidade, sendo visualizada, inclusive, como uma ferramenta de proteção da saúde (BOTSMAN e ROGERS, 2011, p. 8).

Os copos descartáveis, por exemplo, tornaram-se onipresentes em diversos ambientes em que as pessoas têm fácil acesso a pias, onde seria possível se lavar canecas ou copos. Quando o descartável se torna símbolo de saúde, o que não necessariamente é uma afirmação verdadeira, sua utilização exagerada cria impacto na questão ambiental e nos faz refletir o que podemos considerar como progresso no momento e prejuízo no futuro (BOTSMAN e ROGERS, 2011, p. 8).

Os "hábitos de descarte" se tornaram tão comuns que não nos perguntamos mais porque temos tantas coisas que precisamos jogar fora, parecendo anestesiados em relação às 
consequências de tais atos. Fora isso, todas essas coisas que jogamos fora representam apenas uma quantidade pequena, se considerarmos todo o lixo necessário para que elas possam ser produzidas (BOTSMAN e ROGERS, 2011, pp. 9-10).

Segundo pesquisas realizadas pelo Instituto Akatu, a terra precisaria ter $50 \%$ (cinquenta por cento) mais recursos para sustentar o padrão de consumo atual ${ }^{8}$. Já a Organização das Nações Unidas para a Agricultura e alimentação (FAO) constatou e alertou que, ao final de 2009, o número de vítimas da fome ultrapassaria a marca de um bilhão de pessoas. Tais dados, confrontados, demonstram um padrão de consumo acima das necessidades, a par de uma ausência assustadora de itens básicos de sobrevivência, como alimento, situação a gerar, fora de dúvida, um contexto de desenvolvimento social preocupante (SOARES-BAPTISTA, 2010, p. 363).

A responsabilidade social (empresarial), enquanto consciência da necessidade de assunção de práticas sustentáveis ou menos predatórias, embora tenha primordialmente a característica de voluntariedade das empresas, dos agentes de mercado, pode ser, ainda, estimulada pela atuação do Poder Público, de órgãos estatais vocacionados à defesa de direitos fundamentais de forma geral e especificamente do consumidor, da ordem econômica e do meio ambiente.

Interessante e inovadora foi a atuação do Ministério Público Federal (MPF) no Estado do Pará, que foi batizada de "Municípios Verdes/Carne legal”, iniciado em junho/2009, por um Grupo de Trabalho denominado Amazônia Legal, coordenado pelo Procurador da República Daniel César Azeredo Avelino, que recebeu premiação especial da IX Edição do "Prêmio Innovare", no ano de $2012^{9}$ e o $1^{\text {o }}$ lugar do Prêmio do Conselho Nacional do Ministério Público (CNMP), na categoria “Transformação Social”, no ano de 2013.

A atuação voltou-se para a busca de uma pecuária mais sustentável ou menos degradadora, teve e tem como foco principal a redução do desmatamento, atingindo num primeiro momento o setor produtivo do estado do Pará e, em um momento posterior, da Amazônia.

Assim, o MPF identificou as áreas em que haviam exploração de atividade pecuária em desrespeito às normas ambientais e trabalhistas, propôs ações civis públicas de

\footnotetext{
${ }^{8}$ Informação obtida em 25 de agosto de 2013, no site: http://www.akatu.org.br/Temas/Sustentabilidade/Posts/Terraprecisaria-ter-50-mais-recursos-para-sustentar-padrao-de-consumo-atual.

${ }^{9}$ INSTITUTO INNOVARE (Brasil) (Comp.). Municípios verdes: Acordo entre MPF, Governo do Pará e 90 Municípios reduz em mais de 40\% desmatamento na Amazônia. 2012. Autor do Projeto: Daniel César Azeredo Avelino. Disponível em: <http://www.premioinnovare.com.br/praticas/municipios-verdes-acordo-entre-mpfgoverno-do-para-e-90-municipios-reduz-em-mais-de-40-desmatamento-na-amazonia/>. Acesso em: 11 maio 2015 .
} 
responsabilização e expediu recomendações às grandes redes varejistas, exortando-as a não participar da cadeia produtiva ilegal e a informar seus consumidores que não compactuavam com tal prática.

A iniciativa consta do banco de projetos ${ }^{10}$ do CNMP, descrita como uma atuação do MPF que mobilizou as grandes empresas varejistas do país (mais de 70, dentre elas Wall Mart, Carrefour, Pão de Açúcar), que assumiram publicamente que controlariam seus fornecedores de carne bovina, negando-se a adquirir o produto, matéria-prima, provenientes de áreas rurais desmatadas ilegalmente e sustentadas por trabalho escravo ou, ainda, quando a atividade pecuária estivesse em propriedades localizadas em áreas tradicionalmente ocupadas por populações indígenas, quilombolas, bem como proveniente de grilagem de terra pública.

Foram então celebrados Termos de Ajuste de Conduta (TAC) entre o MPF e mais de cem empresas frigoríficas, que se comprometeram a fazer referido controle em relação aos seus fornecedores.

A partir de tais Termos de Ajuste o MPF mobilizou quase 100 municípios e órgãos públicos estabelecendo metas para os municípios e para os produtores rurais, quais sejam: a) cadastramento de, no mínimo, $80 \%$ da área do município no Cadastro Ambiental Rural ${ }^{11}$ (CAR); b) redução do desmatamento para no máximo $40 \mathrm{~km}^{2}$, no primeiro ano; e c) a inclusão de educação ambiental nas escolas. A contrapartida ao cumprimento das metas seria o desembargo de suas propriedades, acesso facilitado ao crédito rural, segurança jurídica na comercialização, prioridade na regularização fundiária e incentivos econômicos e tributários.

O órgão ministerial promoveu audiências públicas nos municípios expondo as vantagens que seriam obtidas com o fim do desmatamento. E o resultado tem se mostrado alvissareiro, diante da modificação significativa do quadro de degradação ambiental, com a Amazônia atingindo os menores índices de desmatamento de toda sua história, sendo certo que o Estado do Pará, em um único ano, conseguiu reduzir o desmatamento em $40 \%$.

Trata-se, portanto, de uma atuação inspiradora, pois, valendo-se ainda de intensa campanha publicitária, com o auxílio de ONGs, conseguiu o MPF convencer,

${ }^{10}$ INSTITUTO INNOVARE (Brasil) (Comp.). Municípios verdes: Acordo entre MPF, Governo do Pará e 90 Municípios reduz em mais de 40\% desmatamento na Amazônia. 2012. Autor do Projeto: Daniel César Azeredo Avelino. Disponível em: <http://www.premioinnovare.com.br/praticas/municipios-verdes-acordo-entre-mpfgoverno-do-para-e-90-municipios-reduz-em-mais-de-40-desmatamento-na-amazonia/>. Acesso em: 11 maio 2015.

11 BRASIL. Lei no 12.651, de 25 de maio de 2012. Dispõe sobre a proteção da vegetação nativa; altera as Leis nos 6.938, de 31 de agosto de 1981, 9.393, de 19 de dezembro de 1996, e 11.428, de 22 de dezembro de 2006; revoga as Leis nos 4.771, de 15 de setembro de 1965, e 7.754, de 14 de abril de 1989, e a Medida Provisória no 2.166-67, de 24 de agosto de 2001; e dá outras providências. Diário Oficial da União, Brasília, DF, n. 102, 28 maio 2012. Seção I, pp. 1-8. 
estrategicamente, as empresas do ramo atacadista e varejista, do mercado de cortes de carne bovina, da responsabilidade social que detinham para influir de forma significativamente positiva na triste realidade da região, estratégica sob o ponto de vista ambiental e de recursos naturais, que detinha altos índices de desmatamento, diante da incapacidade estatal de ali fiscalizar e impor métodos coercitivos que efetivamente coibissem as práticas que desrespeitavam a legislação ambiental.

Ao mesmo tempo a iniciativa tutelou os interesses sociais de trabalhadores, das populações indígenas e tradicionais da região, a regularização registral das propriedades, o combate à grilagem de terras públicas, além de disseminar posturas de educação ambiental, visando estabelecer um novo patamar ético nas atividades econômicas do ramo da pecuária, um dos mais importantes do país, já que no ano de 2013 foram exportadas mais de 1,5 bilhão de toneladas de carne bovina, gerando divisas para o País da ordem de 6,7 bilhões de dólares, enquanto no ano de 2014 superou-se 1,56 bilhão em toneladas e 7,2 bilhões de dólares, conforme dados da Associação Brasileira das Indústrias Exportadoras de Carne (ABIEC) $)^{12}$

E tudo em consonância com a Convenção da Biodiversidade, resultante do acordo aprovado durante a RIO-92, por 156 países, ratificada pelo Congresso Nacional Brasileiro e promulgada através do Decreto $\mathrm{n}^{\mathrm{o}} 2.519$, de 16 de março de 1998. Dentre outros, são objetivos dessa Convenção a conservação da diversidade biológica e a utilização sustentável de seus componentes (artigo $1^{\circ}$ ), devendo-se desenvolver estratégias, planos ou programas para a conservação e a utilização sustentável da diversidade biológica ou adaptar para esse fim estratégias e planos existentes, integrando, na medida do possível e conforme o caso, a conservação e a utilização sustentável da diversidade biológica com esses planos, através de programas e políticas setoriais ou intersetoriais pertinentes $\left(\operatorname{artigo} 6^{\circ}\right.$ ).

De mais a mais, é preciso reconhecer que o desenvolvimento não precisa ser contraditório com a sustentabilidade. Essa conciliação é possível desde que o desenvolvimento se converta num afastamento de tudo aquilo que aprisiona e bloqueia o florescimento integral dos seres vivos. Por este caminho de reestruturação, o desenvolvimento torna-se sustentável, contínuo e duradouro (FREITAS, 2012, p. 42).

Felizmente, existe hoje uma nova consciência de que é possível se utilizar, para a mensuração do desenvolvimento de um país, indicadores alternativos mais confiáveis que o $\mathrm{PIB}$, o qual, ao seu tempo, representou um considerável progresso, apesar de simples e

12 ASSOCIAÇÃO BRASILEIRA DAS INDðSTRIAS EXPORTADORAS DE CARNE (ABIEC). Exportações Brasileiras de Carne Bovina Brazilian Beef Exports. 2014. Fonte / Source: SECEX-MDIC. Disponível em: <http://www.abiec.com.br/download/Jan - Dez - 2014.pdf>. Acesso em: 11 jun. 2015. 
limitado em sua métrica sintética, mas que demanda reformulações, a considerar, inclusive, a sustentabilidade, como um dos fatores na avaliação da performance econômica (FREITAS, 2012, pp. 42-43).

Ter um dos maiores PIB do mundo, por exemplo, não significa necessariamente desenvolvimento, do ponto de vista que tal índice não mede a qualidade de vida dos cidadãos, a renda per capta, a probidade nas relações públicas e privadas, a qualidade educacional, o respeito à biodiversidade, a confiabilidade do ambiente negocial etc. (FREITAS, 2012, p. 43).

Importante se frisar a indispensabilidade de se construir um critério de avaliação líquida e qualitativa da atividade econômica, tarefa de fôlego, se consideradas as fortes resistências culturais e preconceitos a sobrepujar, que impedem que aflorem as verdadeiras prioridades constitucionais, prendendo-nos numa visão pessimista e sem soluções sobre o futuro, pouco criativas, como a da chamada tragédia dos bens comuns (FREITAS, 2012, p. 43).

\section{CONCLUSÃO.}

Paralelamente aos esforços que já foram e vêm sendo empreendidos pela sociedade mundial, pelos Estados no âmbito dos organismos internacionais que congregam as nações, sob a perspectiva do desenvolvimento sustentável, fato é que imperiosa se faz profunda reflexão que propicie a busca de um verdadeiro desiderato de mudança de paradigma nas hodiernas relações de consumo e produção, inclusive com um olhar especial sobre o tema da desigualdade social, da pobreza e de seu enfrentamento através de políticas públicas que propiciem o acesso à educação de qualidade, que objetive, para além da qualificação profissional, a formação plena para a cidadania, conforme diretrizes que constam do texto constitucional (art. 205 e 214, V, C.F.)

Outrossim, muito pode ser realizado no plano interno para contribuir na seara da sustentabilidade ambiental, social e econômica, que ao fim e ao cabo constituem premissas para o atingimento dos objetivos fundamentais da República Federativa do Brasil, notadamente a construção de uma sociedade livre, justa e solidária (inclusive com as futuras gerações), erradicadora da pobreza e da marginalização, com a redução das desigualdades e a promoção do bem de todos (art. $3^{\circ}$, C.F.).

Imperioso não olvidar desta forma as amplas e legítimas possibilidades de atuação estatal como indutora de comportamentos dos agentes econômicos, na seara da responsabilidade social (empresarial), de chamamento para contribuir de forma mais efetiva 
para o bem-estar social, colaborando na redução de desigualdades sociais e regionais, bem como para que se potencialize, de forma progressiva, compromissos com a exploração racional dos recursos naturais, com a redução da poluição, propiciando consistente melhoria da qualidade de vida.

Nessa linha, a citada iniciativa do MPF denominada "Carne Legal”, de indução de responsabilidade social (empresarial) com resultados significativamente positivos sobre produção e consumo, demonstra o muito que pode ser construído pelo Poder Público, notadamente através de projetos de lei ou, quiçá, de normas infralegais, em consonância com a legislação posta, para incentivar e chamar os setores produtivos à tarefa de coautores na implementação de um modo diferenciado de produção e de consumo, mais responsável e justo, com respeito ao interesse público, à sociedade e a máxima proteção ao meio ambiente.

A Constituição Federal aponta neste sentido, valendo citar à guisa de exemplo, os parágrafos $2^{\circ}$ e $4^{\circ}$, do artigo 218 , quando sentenciam que a pesquisa tecnológica voltar-se-á preponderantemente para a solução dos problemas brasileiros e para o desenvolvimento do sistema produtivo nacional e regional, motivo pelo qual a lei apoiará e estimulará as empresas que invistam em pesquisa, criação de tecnologia adequada ao País, formação e aperfeiçoamento de seus recursos humanos.

Os entes políticos têm instrumentos para tanto, notadamente através de incentivos tributários, além de subvenções ou empréstimos subsidiados (ainda que temporários), que podem ser direcionados a empresas visando, por exemplo, o desenvolvimento de projetos de racionalidade e economia no uso da água, bem como de eficiência energética para as suas atividades produtivas, mas que detenham potencial para ser replicado para outras empresas, dotados assim de efeito multiplicador no uso mais sustentável de recursos hídricos e de redução da utilização de energia para os processos produtivos e de prestação de serviços.

E, ainda sob o prisma de lege ferenda, os projetos mais eficientes poderiam ser utilizados como modelos a serem observados compulsoriamente para a concessão de novas autorizações, alvarás, licenças, outorgas etc., quando necessárias, para o desenvolvimento de atividades econômicas. Aliás, assim agindo o Estado estaria a concretizar os princípios gerais regentes da atividade econômica, estabelecidos no texto constitucional (art. 170 e incisos). 


\section{REFERÊNCIAS BIBLIOGRÁFICAS.}

ASSOCIAÇÃO BRASILEIRA DAS INDÚSTRIAS EXPORTADORAS DE CARNE (ABIEC). Exportações Brasileiras de Carne Bovina Brazilian Beef Exports. 2014. Fonte / Source: SECEX-MDIC. Disponível em: 〈http://www.abiec.com.br/download/Jan - Dez - 2014.pdf〉. Acesso em: 11 jun. 2015.

ASSOCIAÇÃO BRASILEIRA DE NORMAS TÉCNICAS. (Comp.). ISO 26000:2010. 2010. Disponível em: 〈http://www.inmetro.gov.br/qualidade/responsabilidade_social/iso26000.asp>. Acesso em: 11 jun. 2015.

BAUMAN, Zygmund. Vida Líquida. Rio de Janeiro: Jorge Zahar, 2007.

BORGER, Fernanda Gabriela. Responsabilidade social empresarial e sustentabilidade para a gestão empresarial. 2013. Homepage do Instituto Ethos de Empresas e Responsabilidade Social. Disponível em: <www3.ethos.org.br/cedoc/responsabilidade-social-empresarial-esustentabilidade-para-a-gestao-empresarial>. Acesso em: 10 maio 2015.

BOTSMAN, Rachel e ROGERS, Roo. O que é meu é seu: como o consumo colaborativo vai mudar o nosso mundo. Trad. Rodrigo Sardenberg. Porto Alegre: Bookman, 2011.

BOWEN, Howard R.. Responsabilidades Sociais do Homem de Negócios. Tradução de Octávio Alves Velho. Rio de Janeiro: Civilização Brasileira S/A, 1957.

CARDOSO, Alenilton da Silva. Princípio da solidariedade: o paradigma ético do direito contemporâneo. São Paulo: Juarez de Oliveira, 2010.

COMPARATO, Fábio Konder. A afirmação histórica dos direitos humanos. 9. ed. São Paulo: Saraiva, 2015.

CORTELLA, Mário Sérgio. Dúvida. In: CORTELLA, Mário Sérgio. Pensar bem nos faz bem!: 1. filosofia, religião, ciência e educação. Petrópolis: Vozes, 2013.

DIAS, Guilherme Vieira; TOSTES, José Glauco Ribeiro. Desenvolvimento sustentável: do ecodesenvolvimento ao capitalismo verde. 2010. Disponível em: <http://www.socbrasileiradegeografia.com.br/revista_sbg/Artigos_arquivos/GUILHERME_ar tigo_SBG.pdf >. Acesso em: 10 maio 20.

DINIZ, Marcio Augusto de Vasconcelos. Estado social e o princípio da solidariedade. Nomos: Revista do Curso de Mestrado em direito da UFC. Fortaleza, v. 26, pp. 171-185, janeirojunho de 2007.

DIVISÃO DE DESENVOLVIMENTO SOCIAL E A DIVISÃO DE ESTATÍSTICAS DA COMISSÃO ECONÔMICA PARA A AMÉRICA LATINA E O CARIBE (Org.). Panorama Social da América Latina. 2014. CEPAL. Disponível em: <http://repositorio.cepal.org/bitstream/handle/11362/37706/S1420848_pt.pdf?sequence=1 >. Acesso em: 31 maio 2015.

FEATHERSTONE, Mike. Cultura de consumo e pós-modernismo. Trad. Julio Assis Simões. São Paulo: Studio Nobel, 1995. 
FRANÇA FILHO, Genauto Carvalho de e LAVILLE, Jean-Louis. A economia solidária: uma abordagem internacional. Porto Alegre: Editora da UFRGS, 2004.

FREITAS, Juarez. Sustentabilidade: direito ao futuro. 2 ed. Belo Horizonte, Fórum, 2012.

GRAU, Eros Roberto. A ordem econômica na Constituição de 1988. 11. ed. São Paulo: Malheiros, 2006.

INSTITUTO INNOVARE (Brasil) (Comp.). Municípios verdes: Acordo entre MPF, Governo do Pará e 90 Municípios reduz em mais de 40\% desmatamento. 2012. Autor do Projeto: Daniel César Azeredo Avelino. Disponível em: <http://bancodeprojetos.cnmp.gov.br/visualizarPenProjeto.seam?cid=3165>. Acesso em: 11 maio 2015.

LAGO, André Aranha Corrêa do. De Estocolmo a Joanesburgo: a evolução da agenda de meio ambiente: A Cúpula de Joanesburgo. In: LAGO, André Aranha Corrêa do. ESTOCOLMO, RIO, JOANESBURGO: O BRASIL E AS TRÊS CONFERENCIAS AMBIENTAIS DAS NAÇÕES UNIDAS. Brasília: Fundação Alexandre de Gusmão (funag), 2006.

LOBO, Paulo Luiz Netto Lôbo. Direito civil: parte geral. São Paulo: Saraiva, 2009.

MILARÉ, Édis. Direito do Ambiente: doutrina, prática, jurisprudência, glossário. 6. ed. São Paulo: Revista dos Tribunais, 2009.

MONTIBELLER FILHO, Gilberto. Ecodesenvolvimento e desenvolvimento sustentável: Conceitos Princípios. Textos de Economia, Florianópolis, v. 4, n. 1, p.331-342, 01 jan. 1993. Anual. Disponível em: <https://periodicos.ufsc.br/index.php/economia/article/view/6645/6263>. Acesso em: 10 maio 2015.

OLIVEIRA, Daniele Lopes. ECONOMIA E SUSTENTABILIDADE. 2010. Gestão \& Tecnologia - Faculdade Delta - ISSN 2176-2449. Edição III janeiro/fevereiro 2010. p. 14 a 21. Disponível em: <http://www.faculdadedelta.edu.br/revista/edicao_3/economia_sustentabilidade.pdf $>$. Acesso em: 10 maio 2015.

OLIVEIRA, Leandro Dias de. A Conferência do Rio de Janeiro - 1992 (Eco-92): Reflexões sobre a Geopolítica do Desenvolvimento Sustentável. 2012. Disponível em: <http://www.anppas.org.br/encontro6/anais/ARQUIVOS/GT15-170-3120120626115525.pdf>. Acesso em: 10 maio 2015.

ORGANIZAÇÃO DAS NAÇÕES UNIDAS (Org.). Declaração do Rio sobre Meio Ambiente $e \quad$ Desenvolvimento. 1992. Disponível em: <http://www.onu.org.br/rio20/img/2012/01/rio92.pdf>. Acesso em: 27 maio 2015.

SILVA, José Afonso da. Comentário contextual à Constituição. 6. ed. atual., São Paulo: Malheiros, 2009.

SOARES-BAPTISTA, Rozália Del Gáudio. Sociedade do consumo e gestão de desejos: marcas e publicidade face à sustentabilidade. In: PIMENTA, Solange Maria et al. (coord.). Sociedade e consumo: múltiplas dimensões na contemporaneidade. Curitiba: Juruá, 2010. 
TOMASEVICIUS FILHO, Eduardo. A Função Social da Empresa. Revista dos Tribunais, São Paulo, v. 92, n. 810, p.33-50, abr. 2003.

VEIGA, José Eli da. O principal desafio do século XXI. Revista Ciência e Cultura, São Paulo, v. 57, n. 2, p.4-5, jun. 2005. Trimestral. On-line version ISSN 2317-6660. Disponível em: <http://dx.doi.org/10.1590/S0103-40142014000300002>. Acesso em: 17 maio 2015. 